\title{
ANALYSIS OF A REACTOR PRESSURE VESSEL SUBJECTED TO PRESSURIZED THERMAL SHOCKS
}

\author{
M. NIFFENEGGER ${ }^{1}$, G. QIAN ${ }^{1}$, V.F. GONZALEZ-ALBUIXECH ${ }^{1}$, M. SHARABI ${ }^{2} \&$ N. LAFFERTY $^{2}$ \\ ${ }^{1}$ Paul Scherrer Institut, Laboratory for Nuclear Materials. \\ ${ }^{2}$ Laboratory for Thermal-hydraulics, CH-5232 Villigen PSI, Switzerland.
}

\begin{abstract}
The integrity of reactor pressure vessels (RPVs) of nuclear power plants is one of the most important topics in the field of nuclear energy production. Therefore, the integrity of RPVs has to be assessed for normal operation as well as for emergency transients. A critical transient concerning the RPV integrity is the emergency cooling of a pressurized water reactor, initiated by a leak in the hot leg. Such shock-like cooling in combination with the pressure, the so-called pressurized thermal shock (PTS), causes high thermal stresses in the RPV wall and stress intensities of pre-existing cracks which could exceed the remaining fracture toughness of the material, which is additionally embrittled due to neutron irradiation. This may result in a cleavage fracture of the most safety relevant reactor component.

We present a PTS study of a reference reactor, starting with the calculation of the thermal-hydraulic system behaviour, followed by the simulation of the cold water temperature injection and mixing by means of computational fluid dynamics (CFD) method and the subsequent structural and fracture mechanics calculation. In the safety assessment, we compare the evolution of the stress intensity factors (SIF) during an emergency cooling transient with the fracture toughness at the tip of postulated cracks. Results and open questions will be discussed in the light of a realistic estimation of safety margins. Keywords: computational fluid dynamics, finite element method, fracture mechanics, pressurized thermal shock, reactor pressure vessel, RELAP5.
\end{abstract}

\section{INTRODUCTION}

The fission of atoms in nuclear power plants (NPPs) is a very efficient and clean way (no $\mathrm{CO}_{2}$ emission) of energy production. In Switzerland, $40 \%$ of the electricity is produced in NPPs. However, the drawback is the potential threat to contaminate the environment with radioactive fallout in case of an extreme but rare hazard as occurred in Chernobyl in 1986 and Fukushima in 2011. Such hazards may be initiated by external impact on the NPP, examples are flooding, earthquakes, fire, airplane crash or terrorist attack. Beside external hazards, a release of nuclear material could also be initiated by internal cause. Such a reason would be the brittle failure of the reactor pressure vessel (RPV), which is the most important safety barrier for the nuclear fuel, e.g., caused by a so-called pressurized thermal shock (PTS). Therefore, the RPV has to be assured against its failure by means of a reliable safety assessment. In particular, RPVs have to be assured against a PTS, caused by urgent injection of emergency cooling water, initiated by a potential leak in the hot leg of the coolant loop. The hereby shock-like cooling of the inner RPV wall induces high stresses in it. These thermal stresses are superimposed to those resulting from internal pressure.

A safety assessment in a PTS analysis aims to confirm the integrity of the RPV even in the presence of cracks in its weakest region, which is mostly achieved by applying fracture mechanics (FM) methods. It is important that in such analyses also the ageing of the material 
is taken into account. Ageing of RPV steels in form of embrittlement due to neutron irradiation is a well-known mechanism.

In principle, two different approaches of FM are applied for the integrity assessment of nuclear components, namely deterministic and probabilistic ones [1]. In a deterministic integrity analysis, as applied in European countries, all involved parameters are treated as fixed conservative or best estimate values. The result of the analysis (e.g. the stress intensity factor (SIF) $\mathrm{K}_{\mathrm{I}}$ of postulated cracks) is then compared with an admissible value, which normally is a critical material property (e.g. fracture toughness $\mathrm{K}_{\mathrm{IC}}$ ) divided with an appropriate safety factor. A component is regarded as safe if the calculated SIF $\mathrm{K}_{\mathrm{I}}$ is smaller than the admissible SIF, the fracture toughness $\mathrm{K}_{\mathrm{IC}}$ that is a material property.

In a probabilistic analysis, the concerning parameters are considered as dispersed following a certain distribution function. In a Monte Carlo (MC) calculation the random parameters are varied and thousands of deterministic analyses are performed, whereas the results are judged either as safe or unsafe $\left(\mathrm{K}_{\mathrm{I}}<\mathrm{K}_{\mathrm{IC}}\right.$ or $\left.\mathrm{K}_{\mathrm{I}}>\mathrm{K}_{\mathrm{IC}}\right)$. The probability for a component failure is simply the ratio between the unsafe results and the total number of calculations.

The complete integrity analysis involves several numerical methods. In a first step, the system behaviour of the cooling transient has to be simulated in order to get the time-dependent pressure and temperatures at the inner wall of the RPV for the whole transient. This can be done with the system code RELAP5. However, RELAP5 calculates axisymmetric temperature distribution only and does not consider local cooling caused by the so-called cooling plumes, which are developed below the inlet nozzles of the cold leg. To calculate more detailed temperature fields by considering the mixing of cold and hot water and local cooling

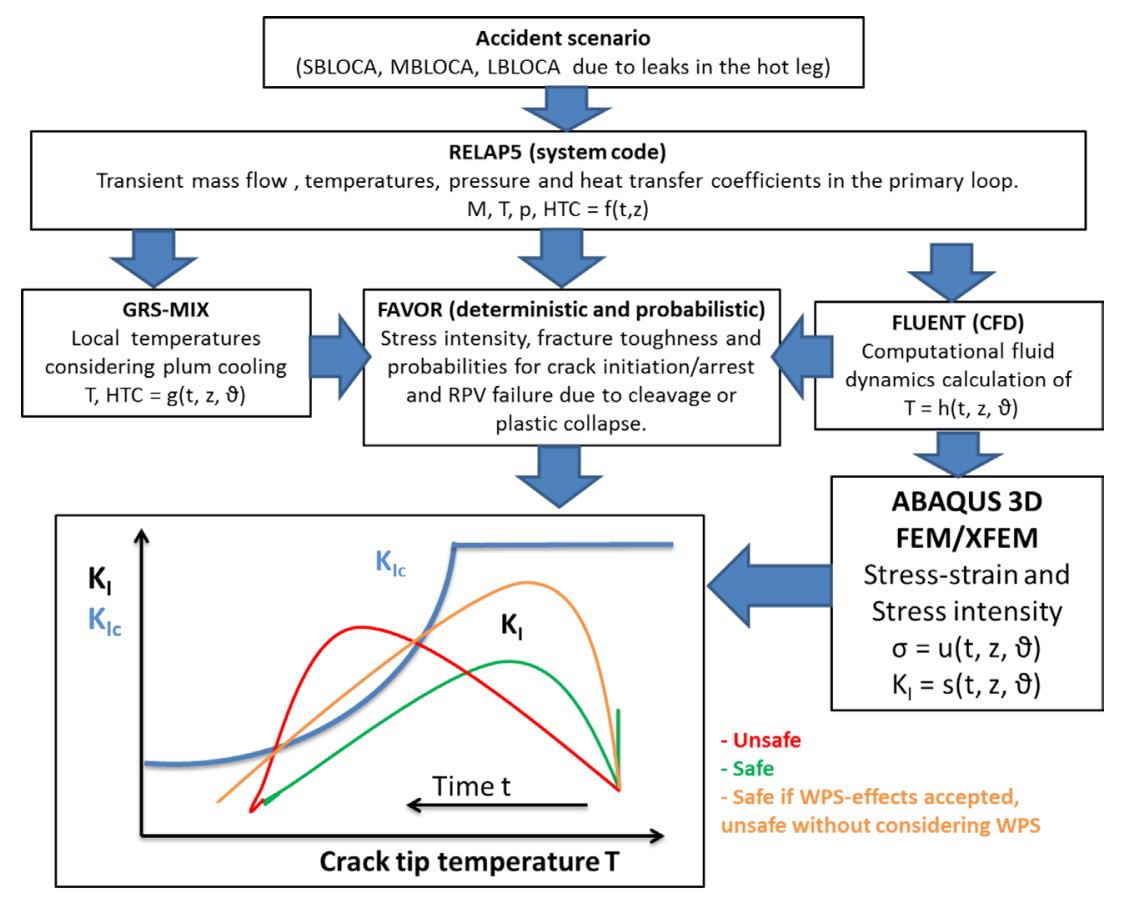

Figure 1: Interplay of the numerical tools for an integrity assessment of a RPV subjected to PTS loading. 
effects, computational fluid dynamics (CFD) simulations are performed to provide full three-dimensional temperature fields in the RPV. These temperatures are needed as input in the FM calculations. An alternative approximate approach to consider the local effect of cooling plumes is realized using the code GRS-MIX [2]. This code is based on an empirical model that allows the calculation of local heat transfer coefficients (HTC) and temperatures based on antecedent RELAP5 calculations to provide the boundary conditions for the computation of stresses.

Structural and FM calculations are mostly performed by means of the finite element method (FEM). However, if the loading conditions and geometry are very simple, FM calculations can be performed with the code FAVOR [3]. This code is based on analytical formulas for the calculation of SIFs of cracks in axi-symmetrically loaded cylinders. The code is designed as a probabilistic tool that allows calculating also probabilities for crack initiation and RPV failure by means of MC simulations.

Figure 1 illustrates the interplay between the numerical models. Note that RELAP5 does not consider cooling plumes and only provides axisymmetric results, whereas CFD and GRS-MIX consider the local cooling effect of the cold plume. The FEM and XFEM provide full 3D stress-strain fields and SIFs, whereas FAVOR calculations result in deterministic SIFs and in probabilities for crack initiation and RPV failure. FAVOR results are based on an axisymmetric model of the RPV in the core region.

In the following, a deterministic analysis of a reference case is presented.

\section{SYSTEM ANALYSIS OF A MODEL REACTOR}

We analyse the thermal-hydraulic system behaviour of a reference two-loop pressurized water reactor (PWR) assuming break leaks of different sizes in one of the hot leg. Figure 2

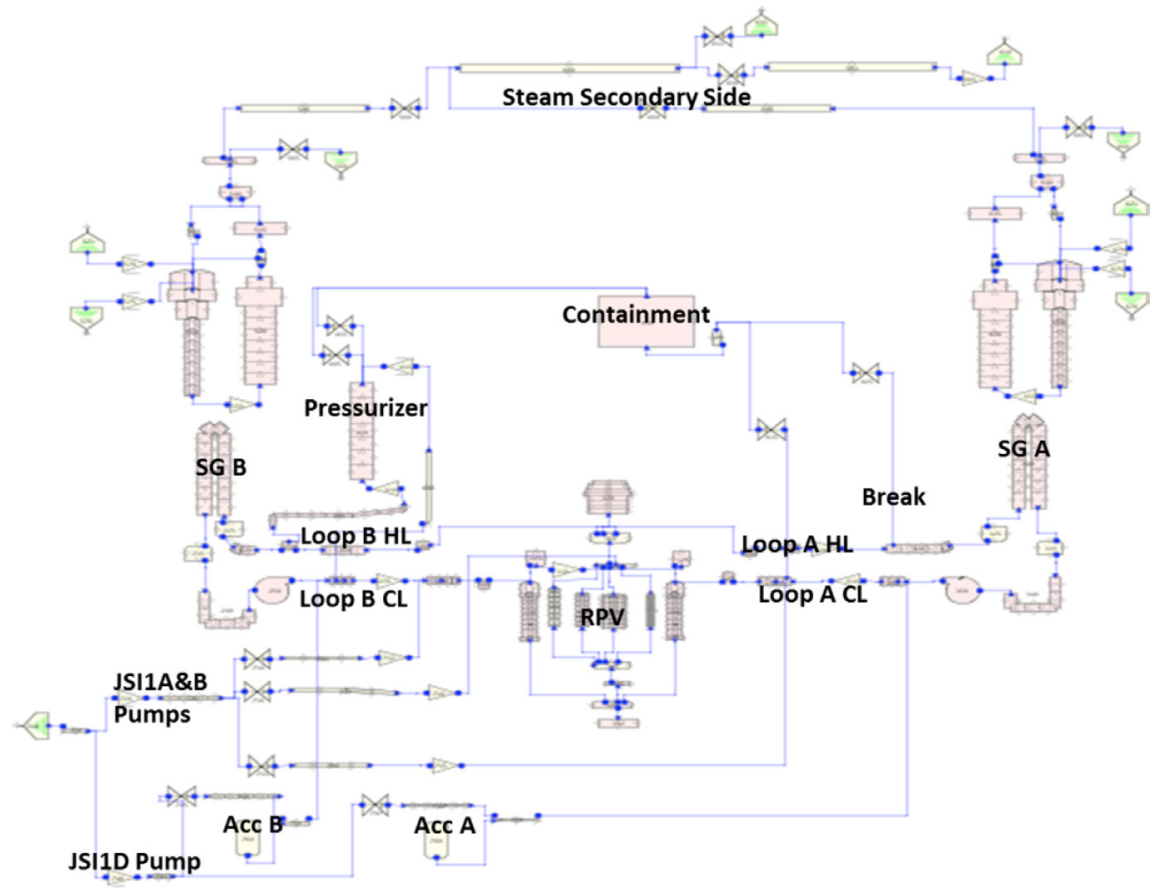

Figure 2: RELAP5 nodalization of a reference two-loop PWR. 


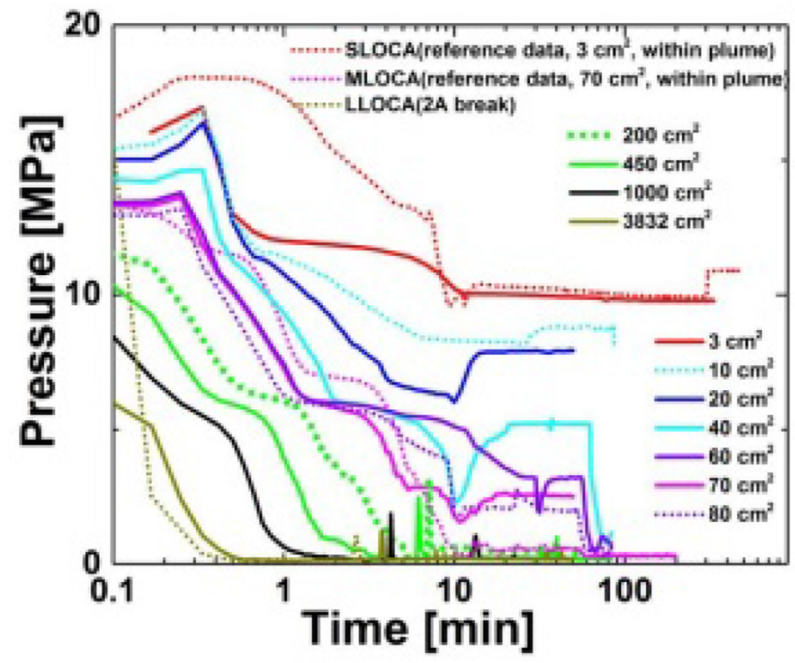

Figure 3: System pressure evolution during different PTS transients.

shows details of the nodalization for the adopted PWR reference design. The two accumulators (Acc) A and B are available to inject cooling water at $10^{\circ} \mathrm{C}$ as soon as the reactor coolant system (RCS) pressure is low enough, that is, below $5 \mathrm{MPa}$. The break is assumed to occur in the hot leg of Loop A, which is the loop without the pressurizer.

For long-term high pressure safety injection, two different safety injection systems (JSIA\&B and JSID) inject $30^{\circ} \mathrm{C}$ water into each cold leg when RCS pressure is below about $10 \mathrm{MPa}$, they become available $4 \mathrm{~s}$ after RCS low pressure signal at $12 \mathrm{MPa}$. The reactor scrams from $100 \%$ power at start of the transient. The main reactor coolant pumps trip off and begin 45 second coast down at the start of the transient.

In the thermal-hydraulic calculations with the system code RELAP5, the following break sizes given in $\mathrm{cm}^{2}$ in the hot leg were postulated: $3,10,20,40,60,70,80,200,450,1,000$, $3,832,2 \times 3,832$ (double guillotine break). Note that the $3 \mathrm{~cm}^{2}$ break leak is hereafter named in this work as small break loss-of-coolant accident (SBLOCA) and the $70 \mathrm{~cm}^{2}$ leak as medium break loss-of-coolant accident (MBLOCA).

The primary output variables from the RELAP5 calculations are: reactor system pressure shown in Fig. 3, primary coolant temperature shown in Fig. 4, and the heat transfer coefficients (HTC) between the primary coolant and the RPV inner wall in the downcomer at core height shown in Fig. 5, the mass flow rate of all injected emergency cooling systems (ECCS) including JSIAB, JSID) and in both accumulators, shown in Fig. 6, the void fractions in the downcomer and the mass flow rate of primary reactor coolant system in each loop.

These results are used as initial and boundary condition input for the CFD calculation and for the deterministic and probabilistic fracture mechanics calculations of $\mathrm{K}_{\mathrm{I}}$ with the code FAVOR.

\section{COMPUTATIONAL FLUID DYNAMICS SIMULATION}

The knowledge of pressure, water temperature and heat transfer coefficient between water and RPV wall, calculated by RELAP5, is in principle sufficient for calculating the impact on the RPV. Actually, many PTS integrity analyses rely on these parameters. However, these 


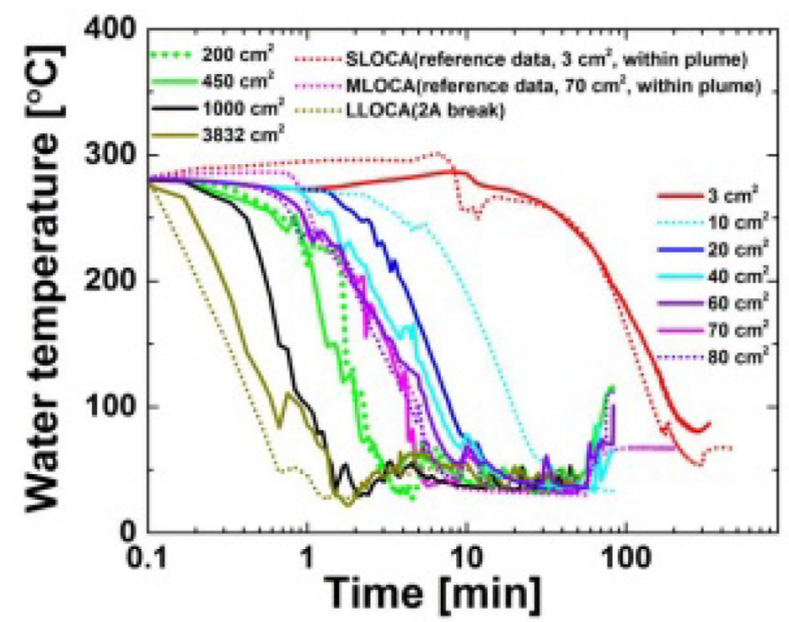

Figure 4: Water temperature at the inner wall in the downcomer at core height for different PTS transients.

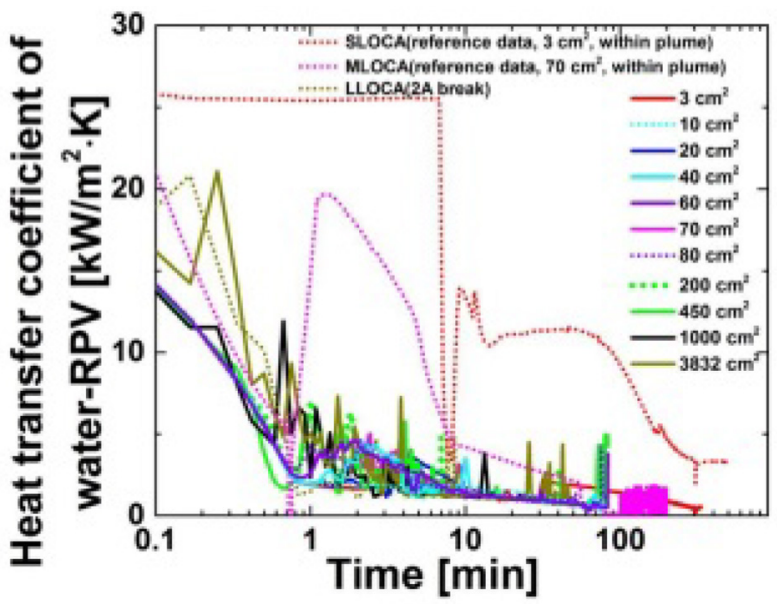

Figure 5: Heat transfer coefficient at the inner wall in the downcomer at core height for different PTS transients.

results from RELAP5 are averaged and axisymmetric values and are not considering local cooling due to cold water plumes, which are formed when the mixed/cold water flows down from the inlet nozzles under the effect of gravity towards the bottom region of the RPV. For a more realistic calculation of local stresses, it should be taken into account that the emergency cooling does not act homogeneously on the RPV, but will enforce the cooling locally, resulting there in higher stresses. Nowadays CFD allows to realistically simulating the formation of such cooling plumes, although the computational effort is still large.

In order to realistically predict the thermal mixing in the cold leg and the effect of the plume cooling in the downcomer, CFD simulations are performed to simulate the threedimensional behaviour of the PTS transients in the RPV. The results from RELAP5 analyses 


\section{ECCS Flow Rates into Loop B}

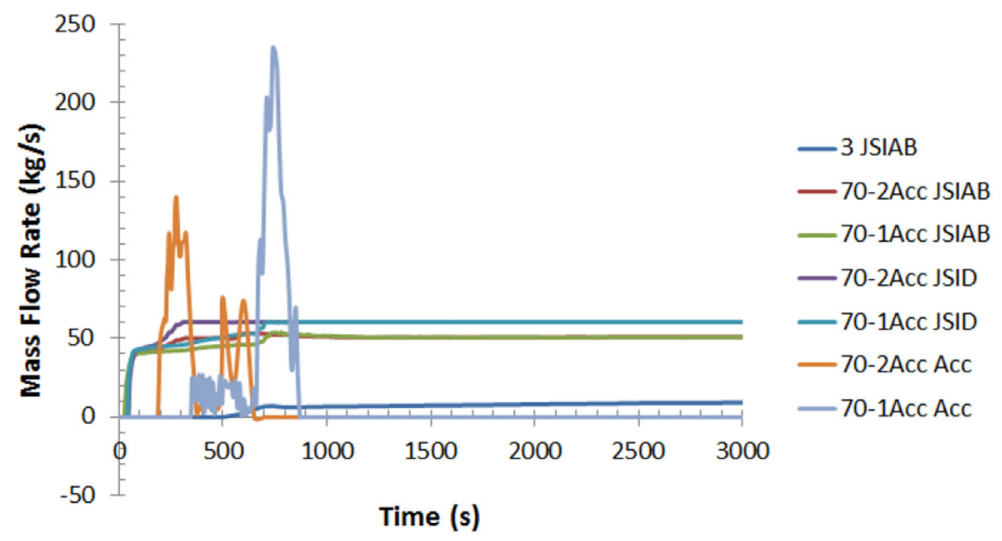

Figure 6: ECCS mass flow rates into cold leg B for high pressure injection pumps A and B combined (JSIA\&B) and pump D (JSID) and the Acc B for the 3 and $70 \mathrm{~cm}^{2}$ leak PTS transients.

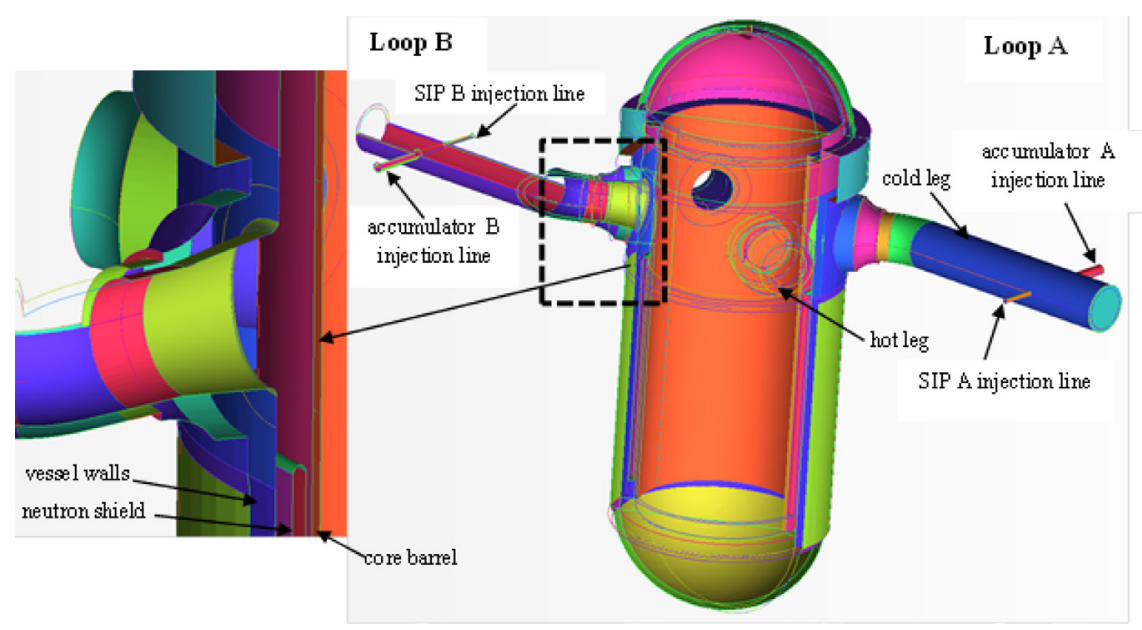

Figure 7: CFD model of the reference RPV.

for SBLOCA of $3 \mathrm{~cm}^{2}$ and the MBLOCA of $70 \mathrm{~cm}^{2}$ in the hot leg are used to define the initial and boundary conditions for the CFD simulations. The CFD model shown in Fig. 7 considers all relevant geometry details of the RPV which have impact on the predictions and a structured mesh, following the best practice guidelines for application of CFD in nuclear safety analyses [4], was constructed as shown in Fig. 8. Mesh sensitivity study was performed showing insignificant change of the results with change of the mesh refinement.

As the CFD simulations require substantial computational resources, the simulations were performed in the most relevant time window of the SBLOCA and MBLOCA transients. The origin of the time window for the simulations was selected at the time when the flow rate in the loops approaches zero. Simulating the initial part of the transient with high flow rate in the loops would enhance mixing between the two streams, resulting in temperature gradients 
which are too small to create significant stresses in the RPV walls. For the SBLOCA case, the ECC injection is accomplished by the high pressure Safety Injection Pumps (SIP) with a mass flow rate of about $12 \mathrm{~kg} / \mathrm{s}$ while the accumulator remain inactive because the pressure of the system stabilizes at a high value of $9.8 \mathrm{MPa}$. On the other hand, for the MBLOCA both the SIPs $(80 \mathrm{~kg} / \mathrm{s})$ and accumulator $(200 \mathrm{~kg} / \mathrm{s})$ in loop B are available to provide the ECC water. The CFD simulations were conducted for about 2,500 s for SBLOCA and $800 \mathrm{~s}$ for the MBLOCA case. The results of temperature distributions in the RPV wall were interpolated for the FM analyses.

Table 1 presents different boundary conditions for the CFD simulation of a $70 \mathrm{~cm}^{2}$ break in the hot leg. Three cases were calculated, a asymmetric case I in which only one accumulator injects water into loop B, a symmetric case II in which water is injected in both loops A and B and a two-phase case III which considers the phases water and steam with a void fraction of 0.5 .

In Table 2, the boundary conditions used for the calculation of a small break with a size of $3 \mathrm{~cm}^{2}$ in the hot leg are shown. Note that in this case no accumulators are active.

Snapshots of the calculated temperature distributions at the inner RPV wall are shown in Fig. 9 for the SBLOCA at time $\mathrm{t}=118$ and in Fig. 10 for the MBLOC case at $\mathrm{t}=29$ seconds. For the SBLOCA case, thermal stratification prevails in the cold leg due to the low ECC

Table 1: Boundary conditions used in calculation of the MBLOCA.

\begin{tabular}{lcccccc}
\hline & \multicolumn{2}{c}{ CASE I } & \multicolumn{2}{c}{ CASE II } & \multicolumn{2}{c}{ CASE III } \\
\cline { 2 - 7 } & LoopA & LoopB & LoopA & LoopB & LoopA & LoopB \\
\hline Accumulator, m [kg/s] & 0 & 200 & 200 & 200 & 0 & 200 \\
SIP, m [kg/s] & 80 & 80 & 80 & 80 & 80 & 80 \\
Accumulator, T [K] & 283 & 283 & 283 & 283 & 283 & 283 \\
SIP, T [K] & 303 & 303 & 303 & 303 & 303 & 303 \\
Cold leg, m [kg/s] & 0 & 0 & 0 & 0 & 0 & 0 \\
Initial pressure [bar] & & 69 & & & 69 & \\
Initial temperature [K] & & 558 & & & 558 & \\
Void fraction [-] & & 0 & & & 0.5 & \\
\hline
\end{tabular}

Table. 2: Boundary conditions used in calculation of the SBLOCA.

\begin{tabular}{lcc}
\hline & \multicolumn{2}{c}{ CASE I } \\
\cline { 2 - 3 } & Loop A & Loop B \\
\hline Accumulator, m [kgfs] & 0 & 0 \\
SIP, m [kg/s] & 12 & 12 \\
SIP, T [K] & 303 & 30 \\
Cold leg, m [kg/s] & 0 & 0 \\
Initial pressure [bar] & & 98 \\
Initial temperature [K] & \multicolumn{2}{c}{0} \\
Void fraction [-] & \multicolumn{2}{c}{0} \\
\hline \hline
\end{tabular}




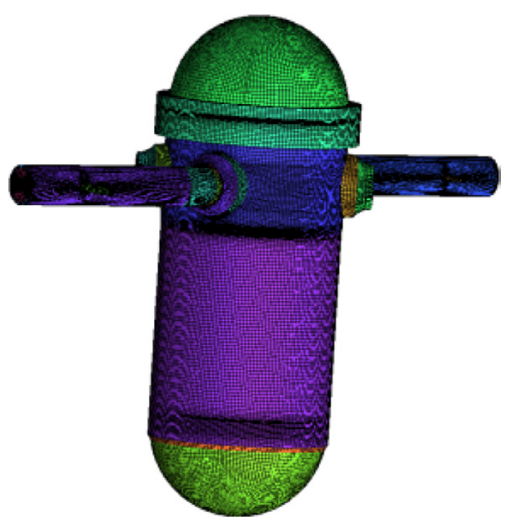

Figure 8: Structured mesh of the RPV for CFD.

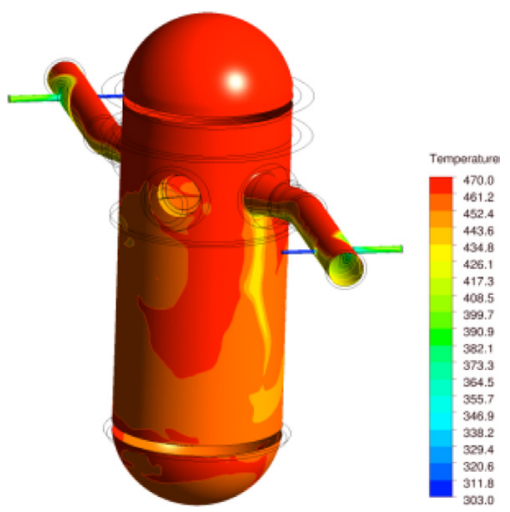

Figure 9: Temperture distribution at the inner RPV wall for the SBLOCA at $t=118 \mathrm{~s}$.

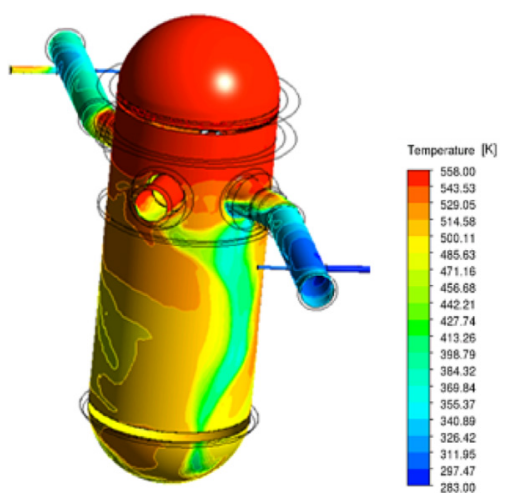

Figure 10: Temperture distribution at the inner RPV wall for the MBLOCA at $t=29 \mathrm{~s}$.

injection flow rate, while for the increased mass flow rate case (MBLOCA) the interface moves towards the cold leg inlet nozzle. Figures 9 and 10 show the development of the cooling plume and the importance of three-dimensional representation of the adopted models to study the PTS phenomenon. 
The CFD simulations showed a pronounced dynamic behaviour of the cooling plume with large temperature differences $\left(\Delta \mathrm{T}\right.$ of about $100^{\circ} \mathrm{C}$ with a frequency of about $0.166 \mathrm{~Hz}$ ) for the MBLOCA. The largest temperature shock of about $230^{\circ} \mathrm{C}$ appears 1 meter below the inlet. Symmetric cooling (loop A and B) results in a faster mixing of the cool water with the hot water, whereas unilateral cooling lead to a more stable cooling plume. Two-phase flow results in a larger thermal shock than the corresponding single-phase case.

\section{STRUCTURAL MECHANICS CALCULATION}

The integrity analysis of the RPV, subjected to PTS transients ranging from 3 to $3,832 \mathrm{~cm}^{2}$ leaks are studied by the FAVOR code, based on temperatures and HTC evaluated by RELAP5 and as well by GRS-MIX. Additionally, FM analysis for the SBLOCA and MBLOCA were performed by means of the FEM based on the temperatures and HTC calculated by CFD.

The material properties used in the structural mechanics calculations are given in Table 3. In PTS analyses, it is common practice to start the calculation at operating conditions (17 $\mathrm{MPa}, 288^{\circ} \mathrm{C}$ ) and to assume that the RPV is stress free at this temperature. Since the mean thermal expansion coefficients given in Table 3 are temperature dependent, special attention has to be paid to their proper use [5].

Figure 11 shows the ring models with the temperatures calculated by CFD and the resulting radial $\left(\sigma_{\mathrm{rr}}\right)$, angular $\left(\sigma_{\theta \theta}\right)$ and axial stresses $\left(\sigma_{\mathrm{zz}}\right)$ for a certain time, calculated by the FEM. Similar values for circumferential and axial stresses can be observed, whereas radial stresses are almost zero and can be neglected. The localized and asymmetric stress distribution resulting from the moving cooling plume shows the importance of three-dimensional CFD analyses.

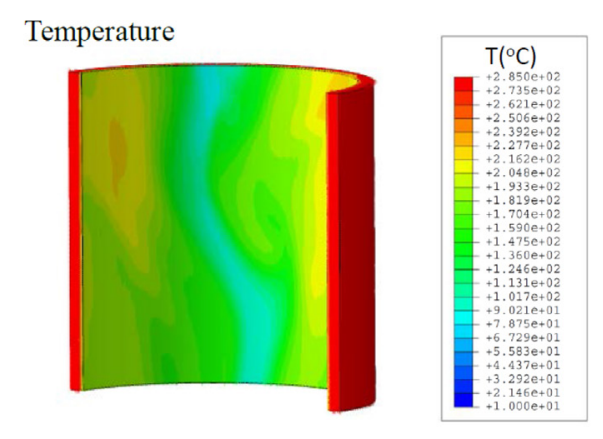

Core Ring Finite Element Model. MLOCA transient, time $351 \mathrm{~s}$

Radial stresses, angular stresses and axial stresses
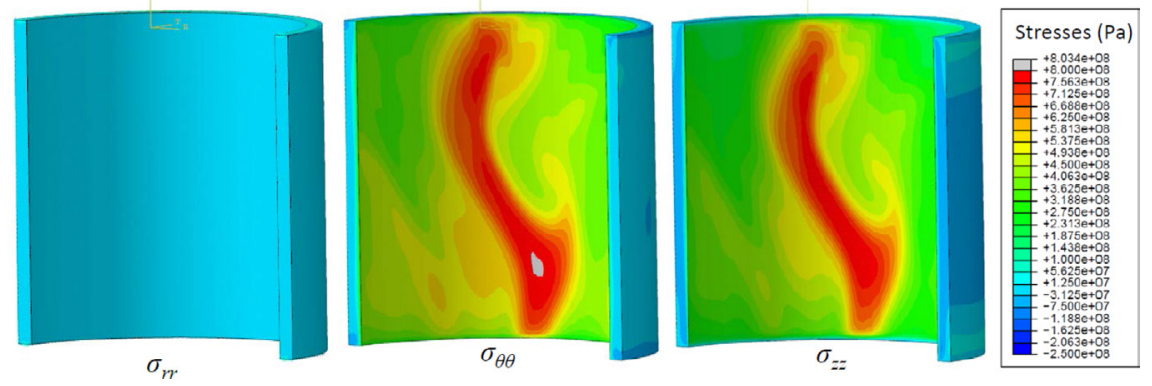

Figure 11: Example of temperature and stress effect of the plume on the inner RPV wall after 351 seconds (MLOCA). 
Table 3: Material properties for structural mechanics calculation.

\begin{tabular}{lllllll}
\hline Temperature $\left[{ }^{\circ} \mathrm{C}\right]$ & 0 & 20 & 100 & 200 & 300 & 400 \\
Elastic Modulus [GPa] & 206 & 206 & 199 & 190 & 181 & 172 \\
Mean linear thermal expansion & 10.3 & 10.3 & 11.1 & 12.1 & 12.9 & 13.5 \\
coefficient $\left[10^{-6} \mathrm{C}^{-1}\right]$ & & & & & & \\
Thermal conductivity $[\mathrm{W} /(\mathrm{m} \mathrm{K})]$ & 44.4 & 44.4 & 44.4 & 43.2 & 41.8 & 39.4 \\
Specific heat capacity $[\mathrm{J} /(\mathrm{Kg} \mathrm{K})]$ & 450 & 450 & 490 & 520 & 560 & 610 \\
Density $\left[10^{3} \mathrm{Kg} / \mathrm{m}^{3}\right]$ & 7.6 & 7.6 & 7.6 & 7.6 & 7.6 & 7.6 \\
Poisson's ratio & 0.3 & 0.3 & 0.3 & 0.3 & 0.3 & 0.3 \\
\hline
\end{tabular}

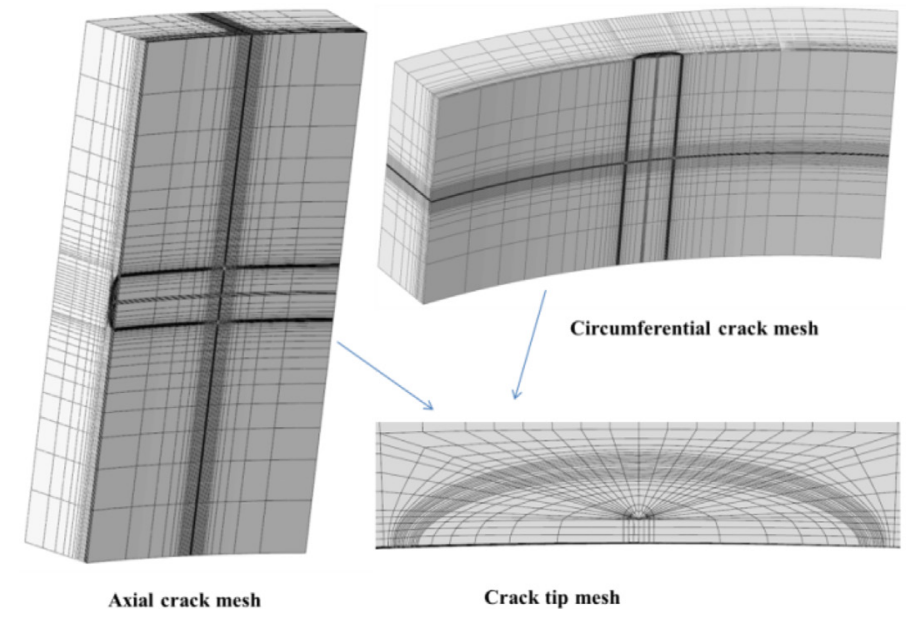

Figure 12: Finite element model of an axial and circumferential crack.

The detailed analysis of the transient stress field allows the evaluation of critical locations for the postulation of cracks used in the subsequent FM analysis.

In the integrity assessment, an axial surface crack with depth of $17 \mathrm{~mm}$ and aspect ratio (length/depth) of 6 is assumed in the most embrittled core region of the RPV. Note that $17 \mathrm{~mm}$ equals to $1 / 10$ of the vessel wall thickness and corresponds to two times the nondestructive detection limit. Figure 12 shows the FEM mesh of the axial and circumferential crack. These cracks were considered in a local ring model of the RPV's core region.

The transient pressure acting on the inner surface of the RPV is also considered in the stress calculation. The resulting axial and circumferential stresses are superimposed on the thermal stresses.

SIFs for the whole transient time are evaluated for the postulated crack. The comparison of mode I SIF $\mathrm{K}_{\mathrm{I}}$ with $\mathrm{K}_{\mathrm{Ic}}$ (the limiting value given for Swiss NPPs by [6]) is shown in Figs 13-15.

Figure 13 shows the SIF versus crack tip temperature calculated by FAVOR and based on temperatures calculated with RELAP5, meaning that plume cooling is neglected. The results are compared with those for SBLOCA and MBLOCA based on temperatures calculated by GRS-MIX (considering plume cooling). In Fig. 14, the SIF vs. crack tip temperatures based on GRS-MIX of all transients are summarized. It is seen that the curves are shifted to lower 
temperatures, meaning that safety margin is reduced. For most of the transients, $\mathrm{K}_{\mathrm{Ic}}$ is higher than $\mathrm{K}_{\mathrm{I}}$, meaning that no crack initiation will occur. However, during the MBLOCA transient, $\mathrm{K}_{\mathrm{I}}$ is higher than $\mathrm{K}_{\mathrm{Ic}}$ for a large part of the time. Thus, with regard to crack initiation, MBLOCA is the most critical transient. In addition to the MBLOCA transient, the transients due to $10 \mathrm{~cm}^{2}, 20 \mathrm{~cm}^{2}$ and $1,000 \mathrm{~cm}^{2}$ leak breaks may also lead to the initiation of the axial surface crack $(\mathrm{a}=17 \mathrm{~mm})$. Therefore, the critical transients concerning crack initiation are MBLOCA, $10 \mathrm{~cm}^{2}, 20 \mathrm{~cm}^{2}$ and $1,000 \mathrm{~cm}^{2}$ leak break transients.

Finally, Fig. 15 shows the resulting SIF based on temperatures evaluated by means of CFD simulations. The observed peak values for $\mathrm{K}_{\mathrm{I}}$ are about $40 \%$ higher than the values that are

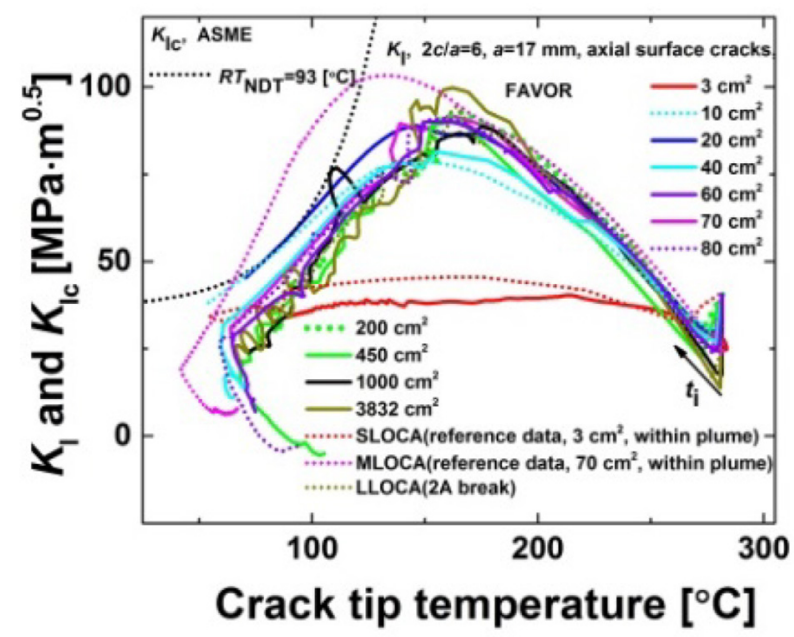

Figure 13: SIFs for a $17 \mathrm{~mm}$ deep axial surface crack in the core region of the RPV due to different sizes of breaks in the hot leg, based on temperatures from RELAP5.

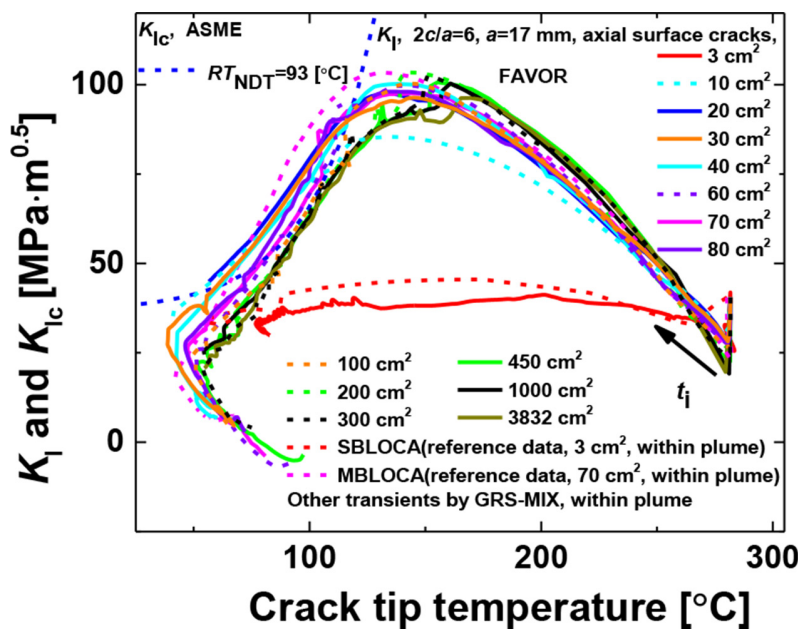

Figure 14: SIFs for a $17 \mathrm{~mm}$ deep axial surface crack in the core region of the RPV due to different sizes of breaks in the hot leg, based on temperatures from GRS-MIX. 


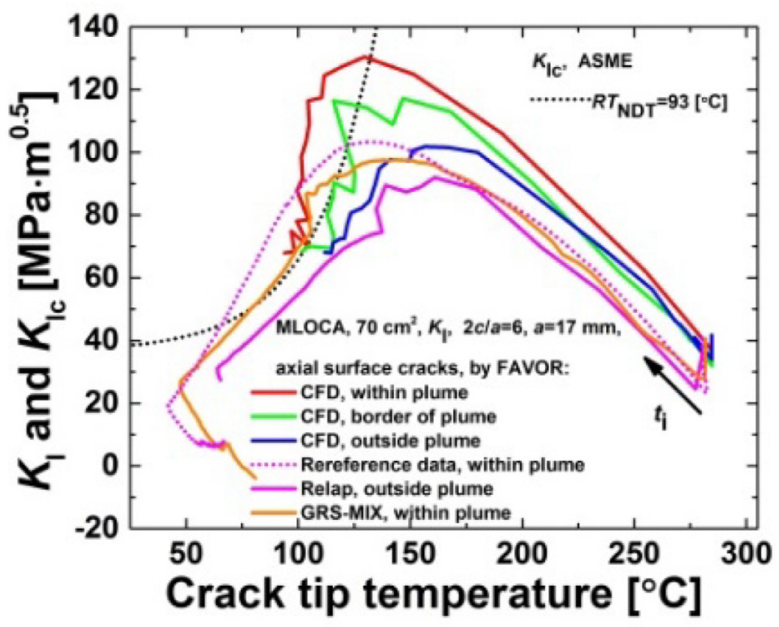

Figure 15: SIFs for a $17 \mathrm{~mm}$ deep axial surface crack in the core region of the RPV by considering plume cooling for a MBLOCA. Temperatures based on CFD.

based on temperatures from axisymmetric models (RELAP5). This tendency is also observed in the results from GRS-MIX. It should be noted that GRS-MIX results are based on empirical correlations whose accuracy are influenced by changes in the geometry and operating conditions. Also it requires input boundary conditions for temperatures of the recirculated flow and outside the plume which are approximated based on one-dimensional analyses from RELAP5. A significant difference between the $\mathrm{K}_{\mathrm{I}}$ of cracks inside, outside and at the border of the plume is observed. Further, it is seen that for cracks inside the cooling plume no safety margins exist with respect to the $\mathrm{K}_{\mathrm{IC}}$ curve.

\section{CONCLUSIONS}

The impact of a PTS on the structural integrity of a RPV was demonstrated. For this purpose, a spectrum of PTS transients, initiated by different postulated leak sizes in the hot leg of a two-loop PWR, was simulated with RELAP5, GRS-MIX, and CFD. Whereas RELAP5 and GRS-MIX provide stable temperature fields, the CFD simulations showed a pronounced dynamic behaviour of the cooling plume with large temperature differences (about $100^{\circ} \mathrm{C}$ and $\approx 0.166 \mathrm{~Hz}$ ). The largest temperature shock of about $230^{\circ} \mathrm{C}$ appears 1 meter below the inlet nozzle. Symmetric cooling (loop A and B) results in a faster mixing of the cool water with the hot water, whereas unilateral cooling lead to a more stable cooling plume.

The comparison of corresponding stress intensities at the crack tip of postulated cracks, based on different thermal-hydraulic tools, showed large differences. It was shown that CFD followed by 3D FEM structural mechanics calculations are necessary for a more realistic evaluation of the inhomogeneous load, that is, by fluctuating cooling plumes. Peak $\mathrm{K}_{\mathrm{I}}$ of the cracks inside the plume increases about 33\% compared with that outside. Furthermore, the analyses have shown that GRS-MIX is an appropriate tool for describing the plume cooling, as long as its verified application range is respected.

The analyses of the transients allowed evaluating the most critical ones, which are MBLOCA, $10 \mathrm{~cm}^{2}, 20 \mathrm{~cm}^{2}$ and $1,000 \mathrm{~cm}^{2}$ leak break transients. Due to these transients, crack initiation may occur if certain cracks exist in the most embrittled part of the RPV. For 
these critical cases the integrity should be assessed by additional crack growth and arrest analyses. The appropriate tool for the latter is 3D-FEM simulations based on temperatures calculated with CFD.

However, there are open questions, that is, the influence of two-phase flow conditions in three-dimensional CFD calculations on the integrity of the RPV is not yet clear, other scenarios than the described ones are not yet analysed, neither operator failure leading to re-pressurization or other effects.

\section{ACKNOWLEDGEMENT}

The authors are grateful for the financial support of the PISA project provided by the Swiss Federal Nuclear Safety Inspectorate (ENSI) (DIS-Vertrag Nr. H-100668). We are also thankful for providing the code GRS-MIX by the Gesellschaft für Anlagen- und Reaktorsicherheit $\mathrm{GmbH}(\mathrm{GRS})$.

\section{REFERENCES}

[1] Qian, G. \& Niffenegger, M., Deterministic and probabilistic analysis of a reactor pressure vessel subjected to pressurized thermal shocks. Nuclear Engineering and Design, 273, pp. 381-395, 2014.

http://dx.doi.org/10.1016/j.nucengdes.2014.03.032

[2] Sonnenburg, H.G., Phänomenologische Versuchsauswertung des Versuchs UPTFTRAM C1 Thermisches Mischen im Kaltstrang. GRS-A-2434, 1997.

[3] Williams, P.T., Dickson, T.L. \& Yin, S., Fracture analysis of vessels-Oak Ridge FAVOR, v 04.1, computer code: theory and implementation of algorithms, methods, and correlations. NUREG/CR -6854, 2004.

[4] Mahaffy, J., Chung, B., Dubois, F., Ducros, F., Graffard, E., Heitsch, M., Henriksson, M., Komen, E., Moretti, F., Morii, T., Muhlbauer, P., Rohde, U., Scheuerer, M., Smith, B.L., Song, C., Watanabe, T. \& Zigh, G., Best practice guidelines for the use of CFD in nuclear reactors safety applications, NES/CSNI/R (2007)5.

[5] Niffenegger, M. \& Reichlin, K., The proper use of thermal expansion coefficients in finite element calculations. Nuclear Engineering and Design, 243, pp. 356-359, 2012. http://dx.doi.org/10.1016/j.nucengdes.2011.12.006

[6] Verordnung des UVEK über die Methodik und die Randbedingungen zur Überprüfung der Kriterien für die vorläufige Ausserbetriebnahme von Kernkraftwerken, (SR 732.114.5), 16.4.2008. 